\title{
Taste and Odor Occurrence in Lake William C. Bowen and Municipal Reservoir \#1, Spartanburg County, South Carolina
}

\section{Problem}

Spartanburg Water treats and distributes drinking water to the Spartanburg area of South Carolina. The drinking water sources for the area are Lake William C. Bowen (Lake Bowen) and Municipal Reservoir \#1 (Reservoir \#1), located north of Spartanburg (fig. 1). These reservoirs, which were formed by the impoundment of the South Pacolet River, were assessed in 2006 by the South Carolina Department of Health and Environmental Control (SCDHEC) as being fully supportive of all uses based on established criteria. Nonetheless, Spartanburg Water had noted periodic taste and odor problems due to the presence of geosmin, a naturally occurring compound in the source water. Geosmin is not harmful, but its presence in drinking water is aesthetically unpleasant.

\section{Study Description}

The U.S. Geological Survey and Spartanburg Water are working cooperatively on an ongoing study of Lake Bowen and Reservoir \#1 to identify environmental factors that enhance or influence the production of geosmin in the source-water reservoirs. Spartanburg Water is using information from this study to develop management strategies to reduce (short-term solution) and prevent (long-term solution) geosmin occurrence.

The cooperative study began as a series of three synoptic surveys (snapshots) of the water quality and algal conditions within each of the reservoirs in 2005 and 2006. These surveys identified sites and water-quality constituents for further monitoring in each of the reservoirs. The information from these three synoptic surveys is available in Journey and Abrahamsen (2008).

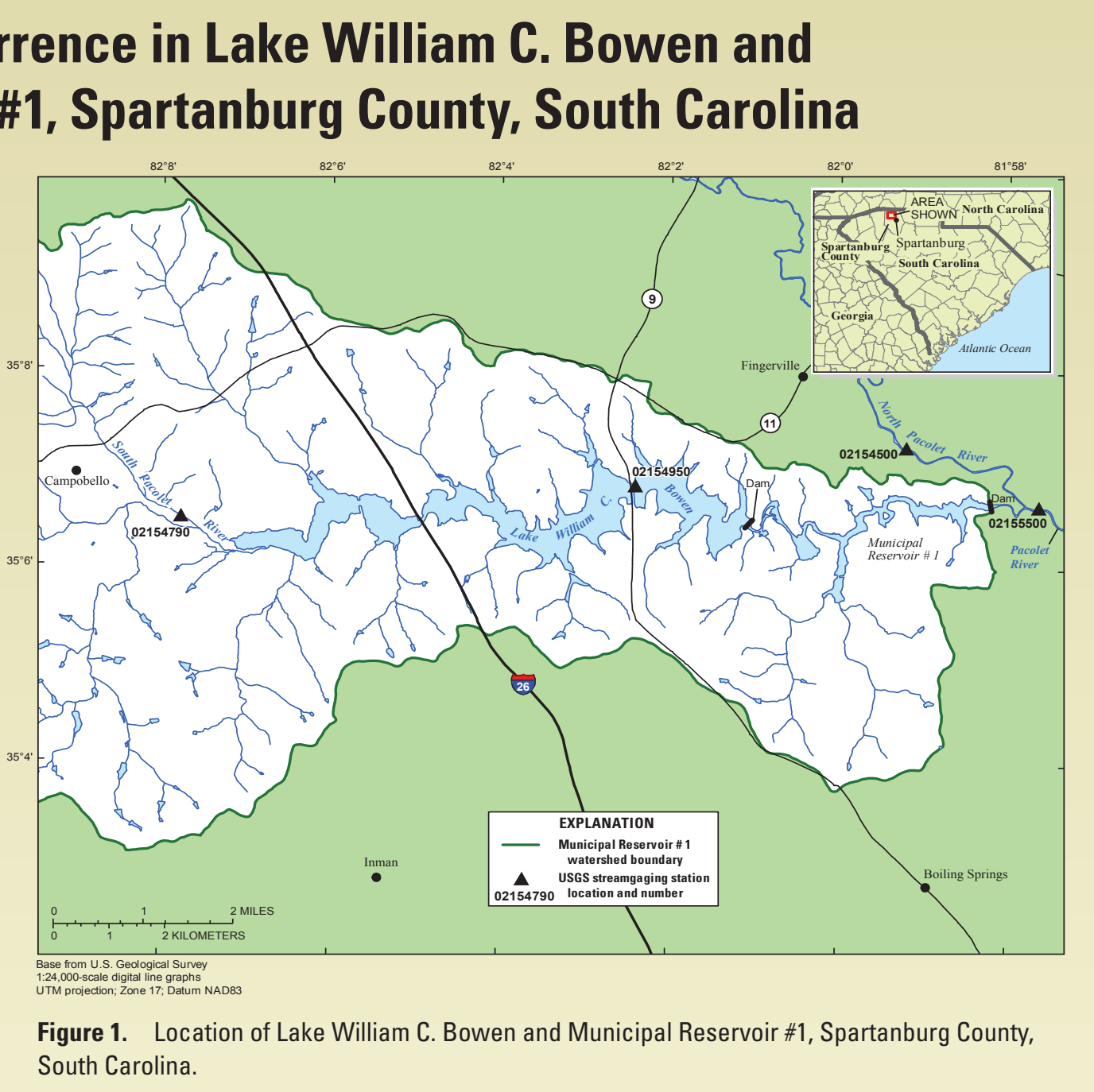

Figure 1. Location of Lake William C. Bowen and Municipal Reservoir \#1, Spartanburg County, South Carolina.

In 2007, a more intensive 3.5-year study that was cooperatively funded at 1.24 million dollars was designed and implemented to provide a better understanding of the factors that influence the production of geosmin in Lake Bowen and Reservoir \#1. Some of the questions to be addressed by the study include the following:

- What is the source of the geosmin?

- Is there a way to predict when problem levels of geosmin will occur?

- Are algal-derived toxins a problem too?
- What reservoir management or treatment strategies (short-term solution) will be most effective in removing or reducing geosmin concentrations below the human taste threshold (10 nanograms per liter) in drinking water?

\section{Background}

Taste and odor are important considerations for water-treatment plants throughout the United States. Second to chlorine, "earthy-musty" is one of the most common tastes and odors for drinking water systems This type of taste and odor is attributed to geosmin, a compound produced by certain types of blue-green algae (cyanobacteria) and soil bacteria (actinomycetes). In fact, 
the earthy smell of soil is from the geosmin production of actinomycetes.

Even when blue-green algae are present in abundance in a lake or reservoir, geosmin production and release to the source water may not occur. The reason is that only certain species of bluegreen algae are capable of producing and releasing geosmin in the lake or reservoir. Additionally, those species produce geosmin periodically, not continually. Certain environmental factors or conditions may influence the growth of blue-green algae and the production and release of geosmin: warm water temperatures, a stable water column (stratified conditions), a low ratio of total nitrogen to total phosphorus concentrations, high total phosphorus concentrations, predation by other organisms, and turbid conditions.

Abundant blue-green algae and the often associated taste and odor problems usually result from nutrient enrichment in lakes and reservoirs. Nitrogen and phosphorus wash off the land surface during storms and are delivered to lakes or reservoirs. Activities on the land, such as fertilizer application, livestock waste, and leaking sewage-disposal systems, often are sources of excess nitrogen and phosphorus that cause the gradual enrichment of lakes or reservoirs.

Nutrient enrichment of lakes and reservoirs produces many water-quality problems. Loss of game fish to less desirable types of fish, like carp, can occur. During the summer months, the warmer temperatures cause lakes to stratify - warmer water near the surface separates from the cooler, denser water near the bottom. In nutrient-enriched lakes during stratified conditions, the dissolved oxygen in the bottom layer

The SCDHEC established the following water-quality critieria for lakes and reservoirs in the Piedmont and Southeastern Plains Ecoregions:

- Total Phosphorus

- Chlorophyll a

- Total Nitrogen

$<0.06$ milligram per liter $<40$ micrograms per liter $<1.5$ milligrams per liter

- Turbidity often is depleted. As the surface-water temperatures cool in the fall, the layers mix and a decrease in dissolved oxygen may be observed throughout the water column. Most game fish cannot tolerate the lower oxygen environment. Under extremely enriched conditions, toxins can be released by blue-green algae, and fish kills can occur due to toxins or depleted dissolved oxygen.

The SCDHEC assesses the lakes and reservoirs of South Carolina to identify extreme nutrient-enriched conditions that may cause these severe problems. Lake Bowen and Reservoir \#1 do not exhibit these conditions based on SCDHEC assessments and U.S. Geological Survey monitoring, but blue-green algae are present and often are abundant. Watershed management of nutrient inputs may be an important preventative strategy to ensure these problems do not occur.

Watershed-scale control of nutrient release to lakes and reservoirs is an important management strategy to reduce or prevent many water-quality problems. This management strategy requires the cooperation of everyone within the watershed to work with local resource managers to achieve the common goal of having a lake or reservoir suitable for multiple uses, including recreation, water supply, and aquatic habitat.

\section{How Much Geosmin Is Too Much? Geosmin is produced in lakes and reservoirs by certain types of algae and soil bacteria. Geosmin is noticeable in drinking water at 2 to 10 parts per trillion (nanograms per liter; Wnorowski, 1992). For comparison purposes, salty tastes are noticeable at 0.25 parts per thousand.}
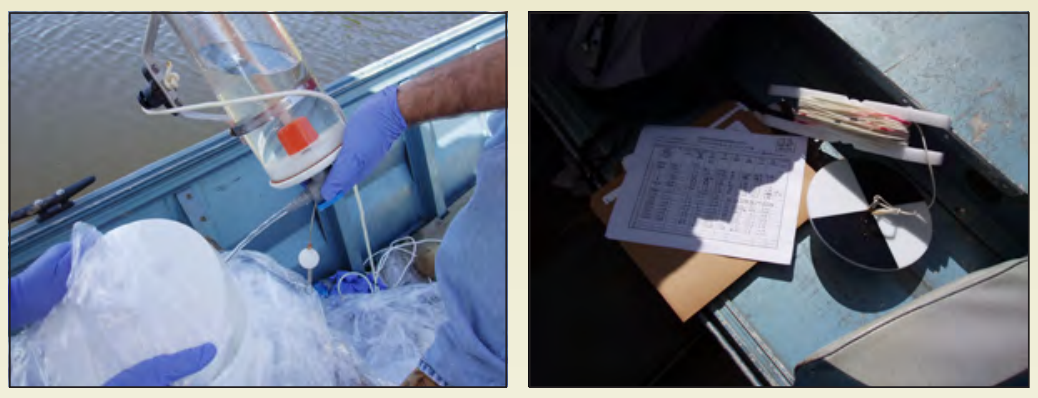

Photos of Van Dorn sampler and churn (left) and Secchi disk and field form.

\section{Cited References}

Journey, C.A., and Abrahamsen, T.A., 2008, Limnological conditions in Lake William C. Bowen and Municipal Reservoir \#1, Spartanburg County, South Carolina, August to September 2005, May 2006, and October 2006: U.S. Geological Survey Open-File Report 2008-1268, 96 p. Available online at http://pubs.water.usgs.gov/ of/2008/1268/

Wnorowski, A.U., 1992, Tastes and odors in the aquatic environment-a review: Water South Africa, v. 18, no. 3, p. 203-214.

\section{Authors}

Celeste A. Journey, Water-Quality Specialist cjourney@usgs.gov

Jane M. Arrington, Ph.D., Spartanburg Water, Technical Services Project Manager jarrington@spartanburgwater.org

\section{For additional information:}

USGS South Carolina Water Science Center Stephenson Center, Suite 129

720 Gracern Road

Columbia, South Carolina 29210

(803) 750-6100

http://sc.water.usgs.gov 